\title{
A THERMOLUMINESCENT NEUTRON DOSIMETRY SYSTEM
}

\section{BY}

C. Distenfeld, W. Bishop and D. Colvett

Health Physics Division

Brookhaven National Laboratory

Upton, New York

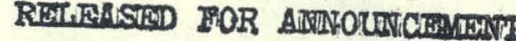 \\ III MUCTISAR SCIEITCE ABSIRACNS}

\section{LEGAL NOTICE}

This report was prepared as an account of Government sponsored work. Neither the United States, nor the Commission, nor any person acting on behalf of the Commission:

A. Makes any warranty or representation, expressed or implied, with respect to the accuracy, completeness, or usefulness of the information contained in this report, or that the use of any information, apparatus, method, or process disclosed in this report may not infringe pilvately uwued 1 iglits, ut

B. Assumes any liabilities with respect to the use of, or for damages resulting from the use of any information, apparatus, method, or process disclosed in this report.

As used in the above, "person acting on behalf of the Commission" includes any employee or contractor of the Commission, or employee of such contractor, to the extent that such employee or contractor of the Commission, or employee of such contractor prepares, dis he with the Commission, or his employment with such contractor. 


\section{DISCLAIMER}

This report was prepared as an account of work sponsored by an agency of the United States Government. Neither the United States Government nor any agency Thereof, nor any of their employees, makes any warranty, express or implied, or assumes any legal liability or responsibility for the accuracy, completeness, or usefulness of any information, apparatus, product, or process disclosed, or represents that its use would not infringe privately owned rights. Reference herein to any specific commercial product, process, or service by trade name, trademark, manufacturer, or otherwise does not necessarily constitute or imply its endorsement, recommendation, or favoring by the United States Government or any agency thereof. The views and opinions of authors expressed herein do not necessarily state or reflect those of the United States Government or any agency thereof. 


\section{DISCLAIMER}

Portions of this document may be illegible in electronic image products. Images are produced from the best available original document. 


\section{A B S T R A C T}

A neutron dosimetric system has been developed by using lithium floride phosphors within a Bonner Sphere. Use of a 12" diameter polyethylene sphere modifies the neutron response characteristics of lithium-bearing material to reasonably resemble the dose equivalent response characteristics of neutrons in tissue. This fortunate response extends from thermal energies to approximately $20 \mathrm{MeV}$. A necessary second characteristic, for a reasonable neutron dosimeter, is the ability to differentiate between neutrons and gamma rays. Use is made of the large difference in neutron absorption characteristics between $\mathrm{Li}^{6}$ and $\mathrm{Li}^{7}$ Floride to permit evaluation of the neutron and gamma dosages for mixed fields. This depends upon a detailed knowledge of the neutron and gamma response characteristics of the two isotopic phosphors. The gamma responses are very similar, except for a minor mass correction, allowing precise gamma subtraction and thereby unmasking the neutron contribution. Neutron response was evaluated by using a positive ion Van de Graaff generator to produce mono-energetic neutrons. Protons on lithium, protons on tritium, deutrons on deutrons and deurrons un tritium allowed coverage nf the range between $150 \mathrm{keV}$ and $18 \mathrm{MeV}$. Sensitivity of the sphere to $1.5 \mathrm{MeV}$ neutrons is about $10 \mathrm{Co}^{60}$ roentgen equivalents per neutron Rad.

In practice the phosphor-bearing spheres may be used at the Alternating Gradient Synchrotron, Cosmotron and at the several reactors to supply neutron and gamma dosimetry information. The instrument's sensitivity range allows for its use as a dusineter for chronic, acute and accidental exposure levels. Excellent rate dependence allows use of the system as a nuclear accident dosimeter. Several major advantages over threshold detectors are realized because of dosage retention, ease of evaluation, and direct rem responding properties. 


\section{A Thermoluminescent Neutron Dosimetry System*}

C. Distenfeld, W. Bishop, D. Colvett

Health Physics Division

Brookhaven National Laboratory

Upton, L. I., New York

Investigation of LiF Thermoluminescent Phosphors in neutron dosimetry was initiated over a year ago. Prior to that, the use of low $Z$ and regular glass microdosimeters in a moderating sphere had been investigated. This system had the serious drawback of not being sensitive enough to low dosages and was incapable of accuracies greater than about $20-30 \%$. Our work with LiF was, therefore, born of specific need to improve both the accuracy and dose response of the neutron dosimeter.

A spare alpha smear counter was converted to the new role of a thermoluminescent reader by replacing the $\mathrm{ZnS}$ screen with appropriate infrared filters and sample slide. A new slide was fabricated from Bakelite to insulate the heater electrodes which were imbedded therein.

Grooves were cut in the underside of the slide to allow $1 / 4^{\prime \prime}$-square busbars to be imbedded. Two 2"-bar segments were inletted in the top of the slide, directly above the recessed bottom rods. Several copper machine screws then connected the upper clamping bars to the lower conducters, affording a considerable amount of heat transfer away frum tlie sample arca. A thin Herrilite plastic wafer, serving as a heat shield, was placed in a recessed separation between the two clamping bars at the top of the slide and a .001"-thick platinum foil was stretched across the bars. Referring to Figure 1, one can observe the details of the slide assembly in loading position. Figure 2 provides a more general view of the entire reader. Starting from the top, one sees the heater, power supply and timer, phototube and high voltage supply, digital voltmeter, Beckman micro-microammeter, our TLD reader and recorder. The plumbing on the

\footnotetext{
* Work done under the auspices of the U.S. Atomic Energy Commission
} 
left of the reader supplies dry nitrogen to both the phototube chamber and the heater cavity. Water cooling is accomplished by drilling the heavy brass base and passing $50^{\circ} \mathrm{F}$ water through the gallery.

The remaining accessory equipment is shown in Figure 3. Use is made of Harshaw types 100,600 and 700 phosphors which consist, respectively, of natural $\mathrm{Li}, 99.91 \% \mathrm{Li}^{6}$ and $99.91 \% \mathrm{Li}^{7}$. For this reason, small tools are rigidly segregated for use with a particular type of phosphor to prevent contamination. The phosphor itself never comes in contact with anything other than stainless steel, platinum or chromium and is kept covered whenever possible. The Mettler balance and capsule loader are the two additional prerequisites to our system. The samples are loaded into thin-walled stainless steel capsules by positioning the capsule under one of the three loading fingers, depending on which type is wanted. Approximately 40 milligrams is deposited in the funnel top with a calibrated dipper. The built-in vibrator is activated for a few seconds to shake any residual phosphor into the sample container. After use, the phosphor is transferred to $1 / 2^{\prime \prime}$ stainless steel planchets. Al1 samples are accurately weighed in the preweighed stainless steel planchets prior to reading.

Glow curves are recorded and TLD peaks are read on a digital voltmeter and inscribed on the glow curve.

Our investigation of the gamma dosage response parallels that reported by Attix in an unpublished review paper during the 1964 Health Physics Society Meeting. Referring to Figure 4, one notices that in the batches used the TLD 600 and 700 phosphors had identical response and that the line has a slope of plus one to $1000 \mathrm{R}$. The points shown do not reflect the extent of the experimental work but serve as a guide. Figure 5 extends the curve downward. 
Standard deviation limits are shown at $25 \mathrm{mR}$ and $100 \mathrm{mR}$.

The neutron response was investigated by exposing TLD 100 and 700 phosphors to monoenergetic neutrons within a $12^{\prime \prime}$ polyethylene moderating sphere. TLD 600 would have been used but was unavailable at the time.

Figure 6 displays the 2", 3", 5", 8" and 12" polyethylene spheres used. Figure 7 allows a close-up view of the sample holder and of the borated polyethylene gamma dosimeter holder. It should be noted that the borated polyethylene rod is threaded to an overlong polyethylene sample holder. This assembly is used only with a $12^{\prime \prime}$ moderating sphere by addition of TLD 700 in the gamma dosimeter holder. Neutron energy response was determined by a positive ion Van de Graaff accelerating protons and dueterons on lithium, tritium and deuterium targets. The energy range of $150 \mathrm{keV}$ to $18 \mathrm{MeV}$ was investigated and the results are shown in Figure 8 along with the Snyder-Neufeld multicollision response described in NBS Handbook 63. The LiF response in the 12" sphere is very similar to the LiI response in a $12^{\prime \prime}$ moderating sphere as reported by Bramlett, Ewing and Bonner in Nuclear Instruments and Methods, Volume 9, 1960. The neutron sensitivity of "ILD 600, exposed in a 12" ophore, is due mainly to moderated fast neutrons. Farben center production in the 600 phosphor is caused by electrons from gamma ray interactions and alpha particles from $\mathrm{Li}^{6}(\mathrm{~N}, \alpha) \mathrm{H}^{3}$. The thermal neutron cross section for this reaction is about 940 barns $^{(1)}$ dropping to less than one barn for a cross section averaged over an energy interval of $10 \mathrm{keV}$ to $15 \mathrm{MeV}$. TLD 700 onl $\mathrm{y}^{(1)}$ undergoes an (N, Y) interaction w1th a 0.03$\}^{1}$ barn cross section. The thermal neutron response of TLD 700 is the sum of the $(N, \gamma)$ response and the effect of the $0.08 \% \mathrm{Li}^{6}$ contamination. This result accounts for a maximum error of about one part per thousand and is neglected in the practical dosimeter. The fast 
neutron sensitivity of TLD 600 to a PuBe neutron source is about $6 \%$. This measurement was accomplished by shielding the TLD 600 and 700 capsules in borated polyethylene, loading the assembly into a Bonner sphere, and exposing the system to neutrons.

In general:

$$
\begin{aligned}
& \text { TLD } 600=\mathrm{N}_{\mathrm{f}}+\mathrm{N}_{\mathrm{t}}+\gamma \\
& \text { TLD } 700=\mathrm{N}_{\mathrm{f}}{ }^{1}+0.001 \mathrm{~N}_{\mathrm{t}}+\gamma
\end{aligned}
$$

For this case, $\mathrm{N}_{\mathrm{t}}=0$ giving:

$$
\begin{aligned}
& \text { TLD } 600=\mathrm{N}_{\mathrm{f}}+\gamma \\
& \operatorname{TLD} 700=\mathrm{N}_{\mathrm{f}}+\gamma
\end{aligned}
$$

Where:

$$
\begin{aligned}
& N_{t}=\text { thermal neutron response of TLD } 600 \\
& N_{f}=\text { fast neutron response of TLD } 600 \\
& N_{f}=\text { fast neutron response of TLD } 700 \\
& Y=\text { gamma response of both phosphors }
\end{aligned}
$$

The gamma compuitent of the PuBe source was calculated to be about $12 \%$ of the total kerma. The phosphors, located in the sphere, will be sensitive to thjs gamma component attenuated and build-up by absorption in polyethylene. Neutron absorption causes a second gamma component which was estimated by application of the depth dose curves of NBS Handbook 63 . Knowing the total gamma fraction, the general equations given above were evaluated as follows:

$$
\begin{aligned}
& N_{f}=6 \\
& \mathrm{~N}_{\mathrm{t}}=92 \cdot \mathrm{N}_{\mathrm{f}^{1}}=27 \\
& \begin{aligned}
\frac{\gamma}{\operatorname{TLD}} 600 & =100 \\
\operatorname{TLD} & \frac{\gamma}{700}=100
\end{aligned}
\end{aligned}
$$

Whenever evaluating an unknown field exposure the response of the TLD 700 is subtracted from that of the 600 . The difference is due to the neutron exposure and is evaluated as per Figure 9. Considering the general equations approximately $75 \%$ of the response of TLD 700 is due to gamma rays. For this 
reason the gamma dose reported by TLD 700 would be overestimated by about $25 \%$ and the neutron component would be underestimated by on $1 \mathrm{y} 0.5 \%$. The accuracy of the system will tend to improve as the gamma component increases. The gamma energy response characteristics of TLD 600 and 700 are so similar that gamma spectra need not be considered when evaluating the neutron exposure by taking differences between the TLD 600 and 700 .

A series of 100 millirem PuBe neutron exposures and various $C^{60}$ gamma doses ranging from 0 - $3000 \mathrm{mR}$ were performed. The net reading obtained by taking simple differences between TLD 600 and 700 correctly indicates the 100 millirem neutron exposure in the presence of the $3000 \mathrm{mR}$ Co ${ }^{60}$ exposure. TLD 700 phosphor contained in the borated polyethylene gamma dosimeter holder correctly reported the $3000 \mathrm{mR}$ gamma exposure.

Use was made of the Oak Ridge Health Physics Research Reactor as a means by which the system response might be compared against knuwn reactor cxposure. A total of 5 runs were accomplished with a dosimeter 4 meters from the reactor core. Dosage varied from approximately 1000 - 1500 Rem in three timed power runs and in two bursts. A naximum error of $20 \%$ was experienced, with an average error of about 10\%. The TLD 700 phosphor contained within the gamma dosimeter holder overestimated the gamma exposure of $20 \mathrm{R}$ by $10 \mathrm{R}$. This was due to capture gamma rays in the 12" sphere and close proximity of the gauma dosimeter holder and sphere. This condition will be helped by using a greater separation between the gamma dosimeter holder and the moderating sphere.

The system described has all of the requirements necessary to allow mixed neutron"gamma or gamma-muon-neutron field dosimetry. The device has particular advantage for measurements that are far from power lines, in high electrical noise areas, and for long term exposures where capital equipment costs would be prohibitive. 
Nuclear accident dosimetry would likely be expressed in dose equivalent units for personnel exposed to nuclear accidents involving low to moderate exposure levels. During most nuclear accidents, outlying areas containing personnel would be well served by a dose-equivalent responding device. The 12 " sphere with combination holder would serve this purpose.

Rad dose is also available from weighted combinations of more than one sphere. Barthoux, Benezech, and Zeborowski, have reported during the Paris 1964 External Source Dosimetry Meeting a means to accomplish this. They suggest reducing the $12^{\prime \prime}$ sphere response by subtracting $5 \%$ of the response of a co-exposed 4.2" sphere.

The area of greatest usefulness for this dose-equivalent device is the field of accelerator dosimetry. Not only will the dosimeter provide accurate and biologically meaningful information, but will do so without concern for

radiation rate effects. Exposure rates of up to $2 \times 10^{8} \mathrm{Rad} / \mathrm{sec}^{(2)} \mathrm{from} \mathrm{a}$ 1b MeV electron beall of $1.3 \mu s c c$ duration have produced negligible rate effects. This will allow the dosimeter to be used satisfactorily with all present pulsed high energy accelerators and could likely be used with future monosecond accelerators.

(1) BNL 325, Neutron Cross Sections

(2) Karzmark, White and Fowler, "Lithium Fluoride Thermoluminescence Dosimetry" Phys. in Med. and Biol. (in press) 


\title{
FIGURES
}

\author{
Figure 1 Thermoluminescent Reader S1ide Assembly \\ Figure 2 TLD Reader and Supporting Electronics \\ Figure 3 Accessory Equipment \\ Figure 4 High Co ${ }^{60}$ Dose Response \\ Figure 5 Low Co ${ }^{60}$ Dose Response \\ Figure 6 Polyspheres of 2, 3, 5, 8, and 12 inch Diameters \\ Figure 7 Polysphere Sample Holder and Borated Polyethylene Gamma \\ Dosimeter Holder \\ Figure 8 Response of LiF Phosphor in a 12" Polyethylene Moderating \\ Sphere \\ F1gure 9 PuBe Ncutron Dose Response of TLD 100, 600, and 700 \\ Phosphors
}




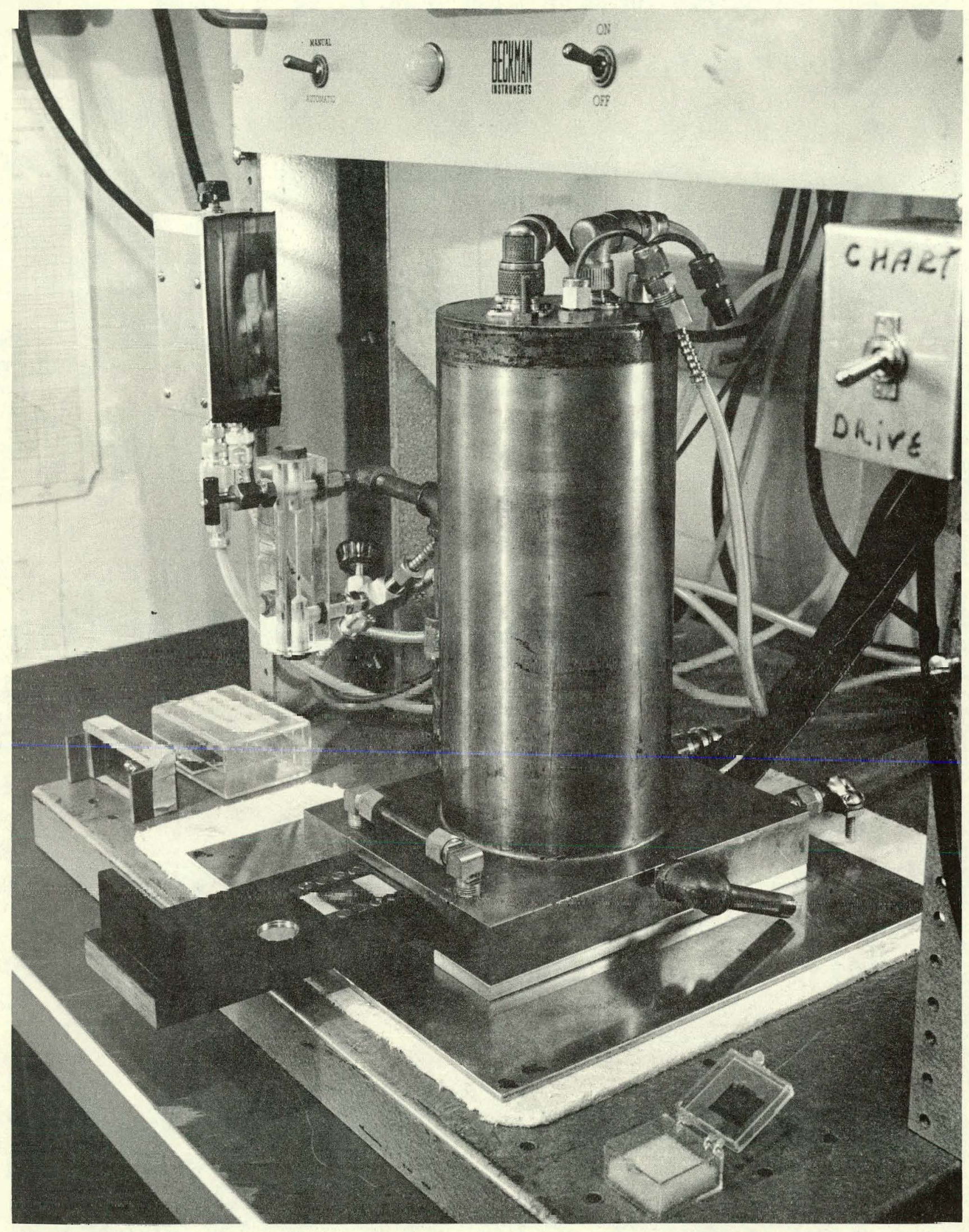




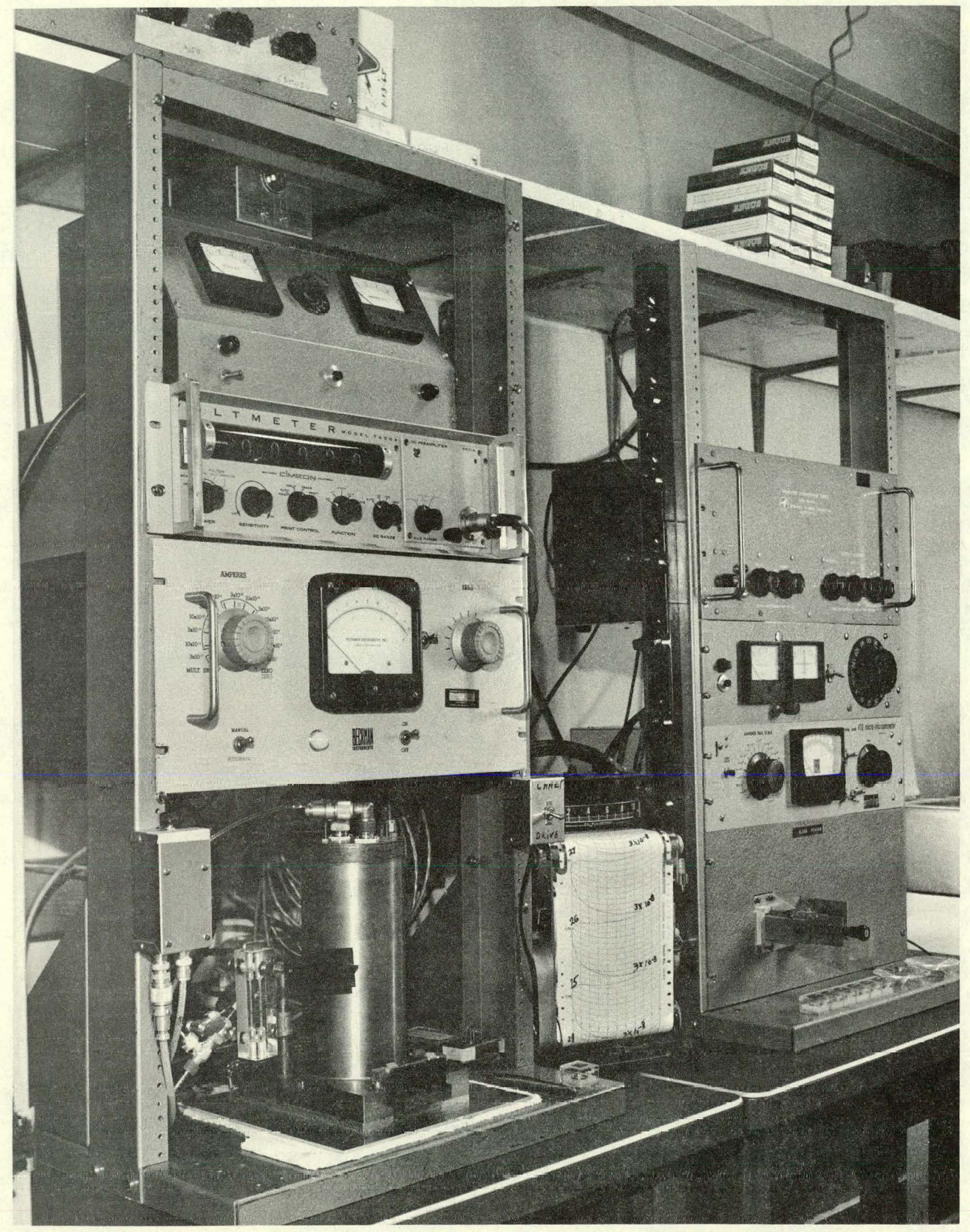

FIGURE 2 


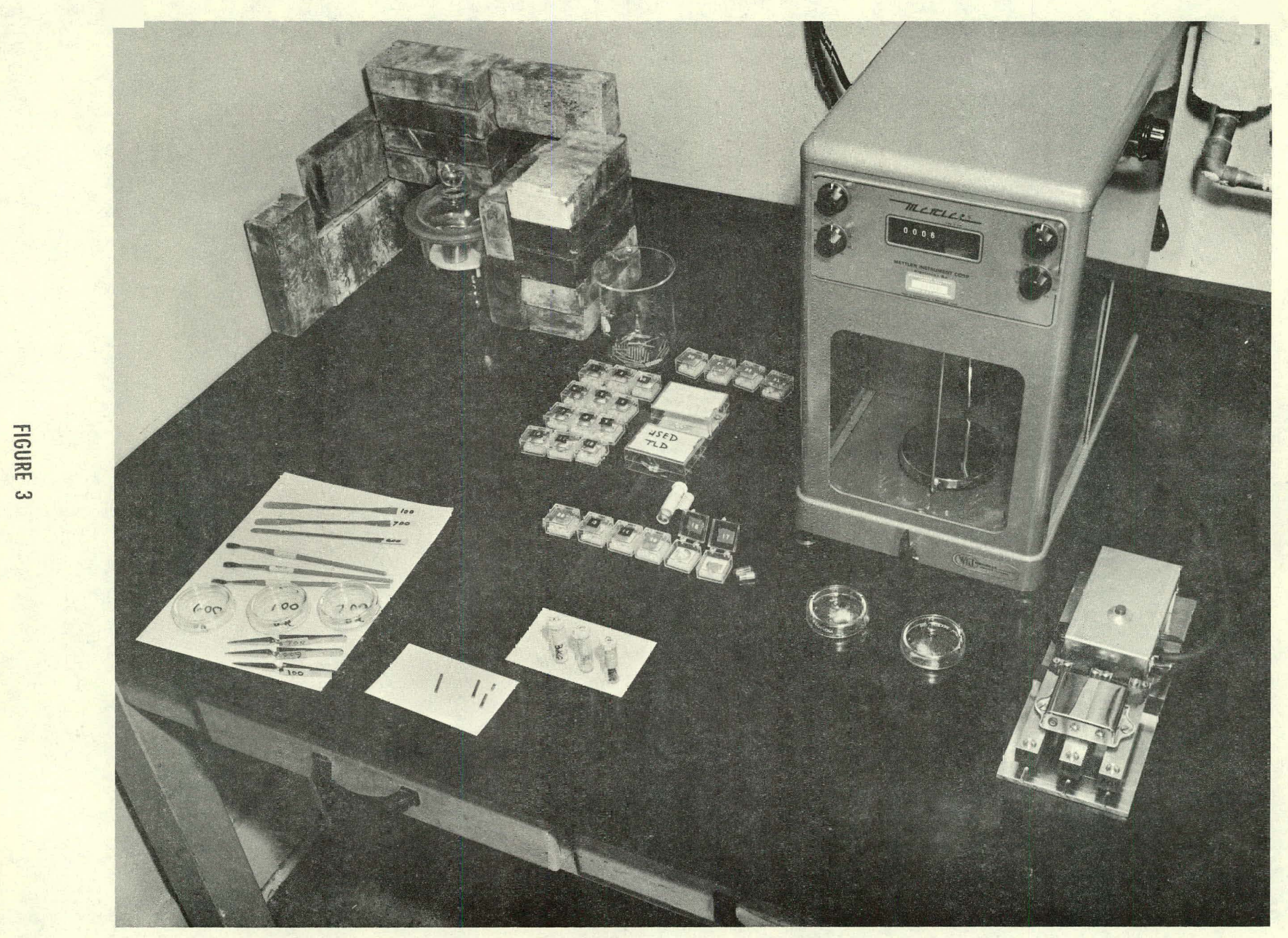




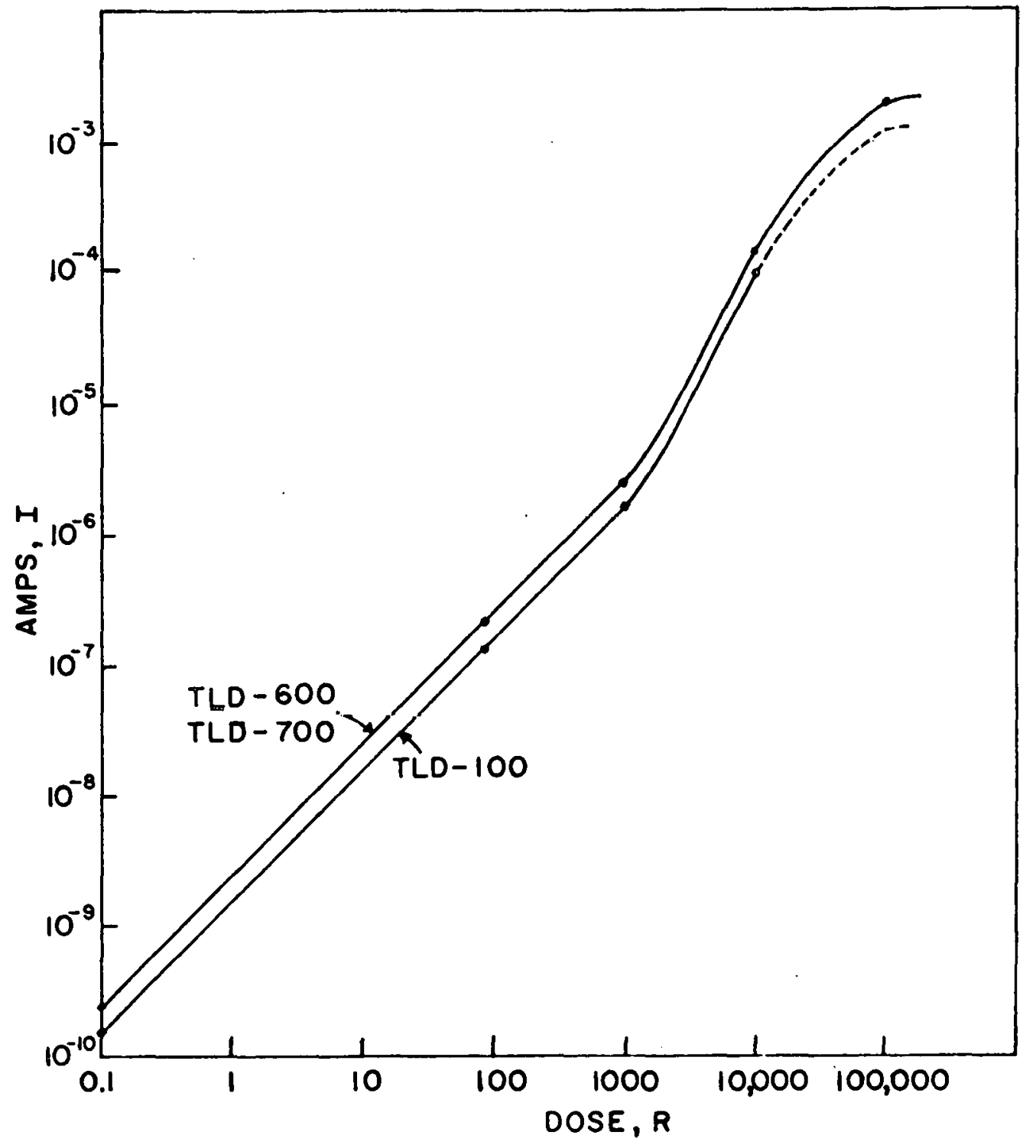

Fig.4. HIGH $\mathrm{CO}^{60}$ DOSE RESPONSE 


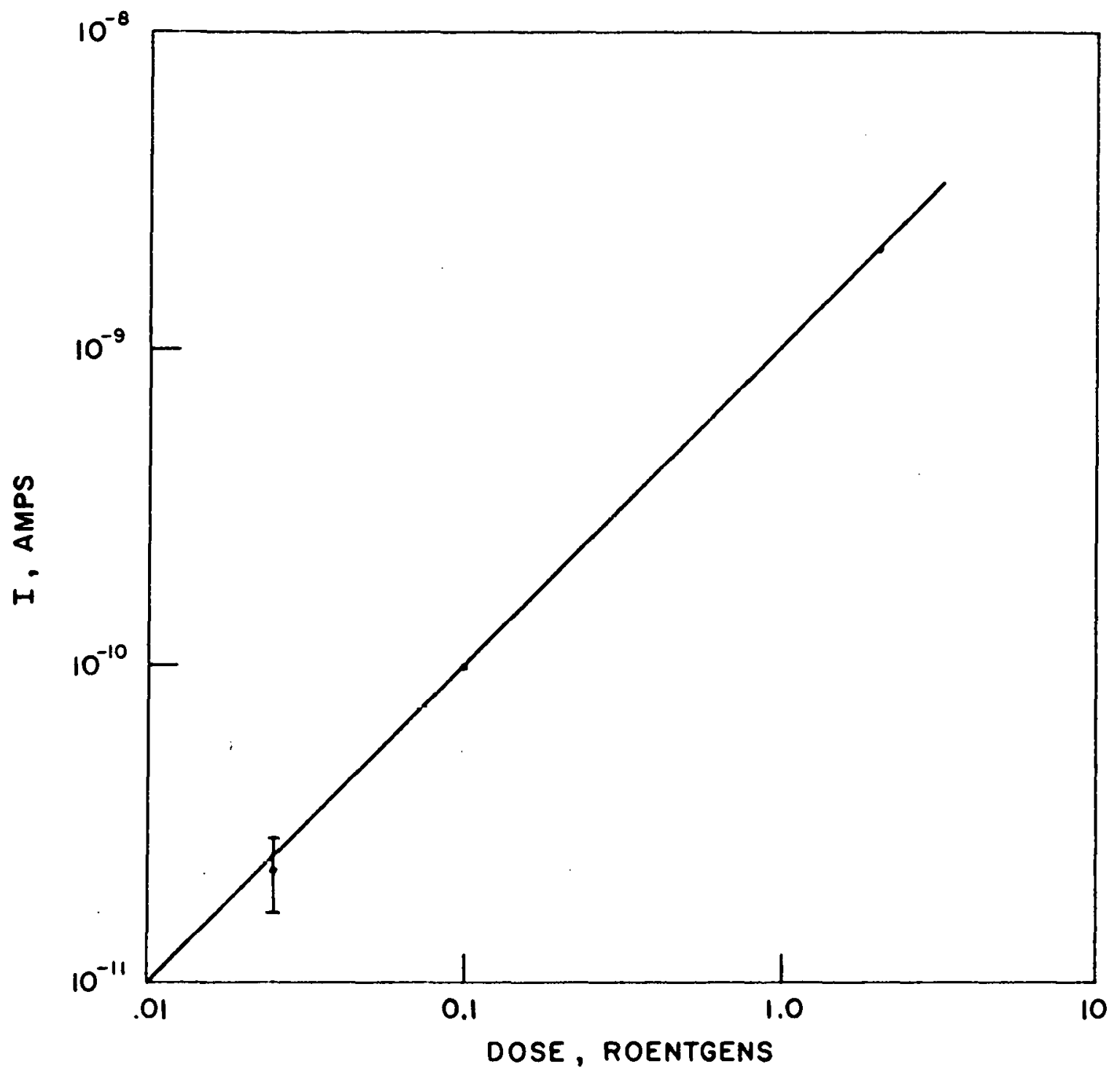

Fig. 5. LOW $10^{\circ 0}$ DOSE RESPONSE TLO-100 


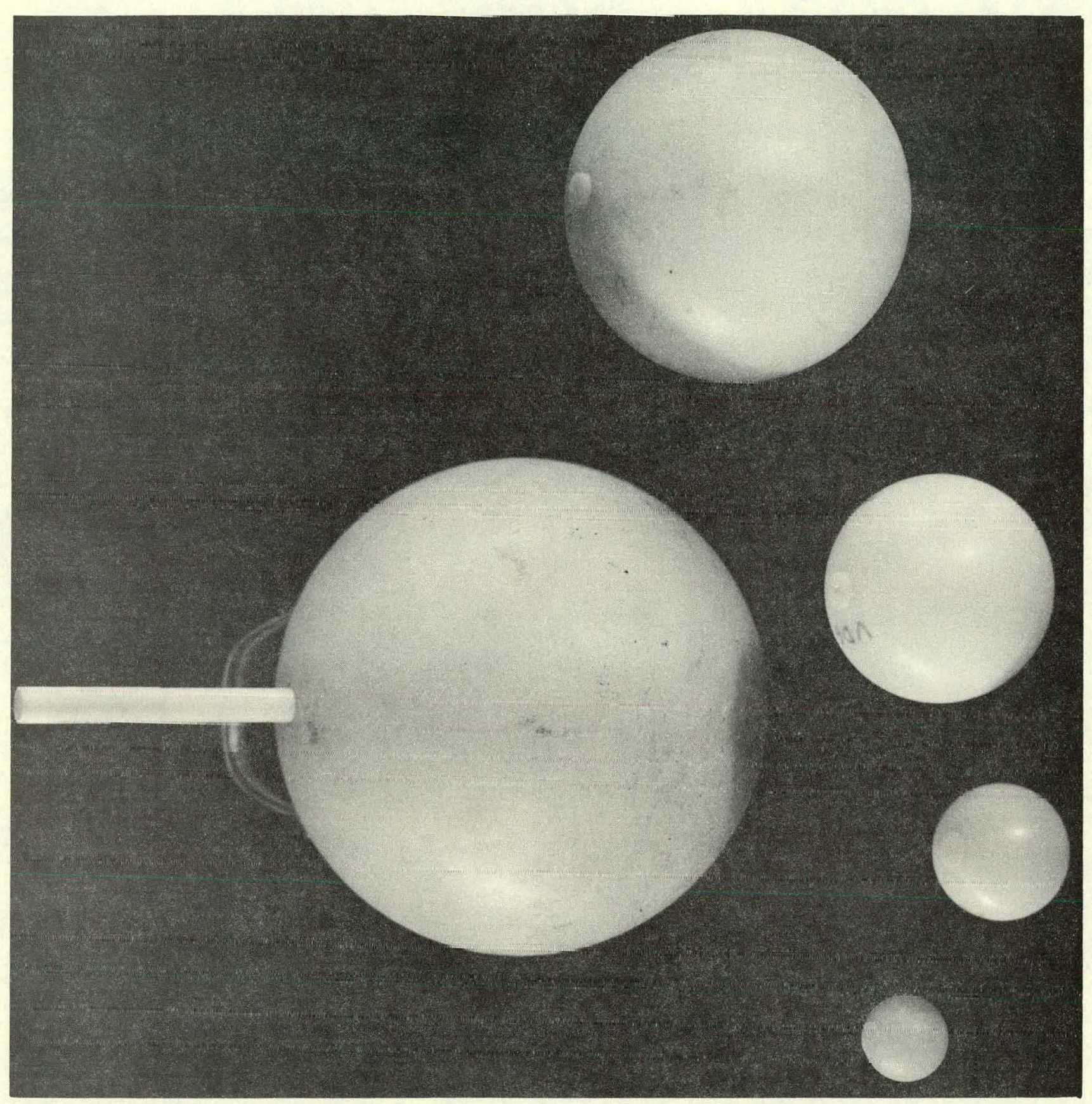

FIGURE 6 


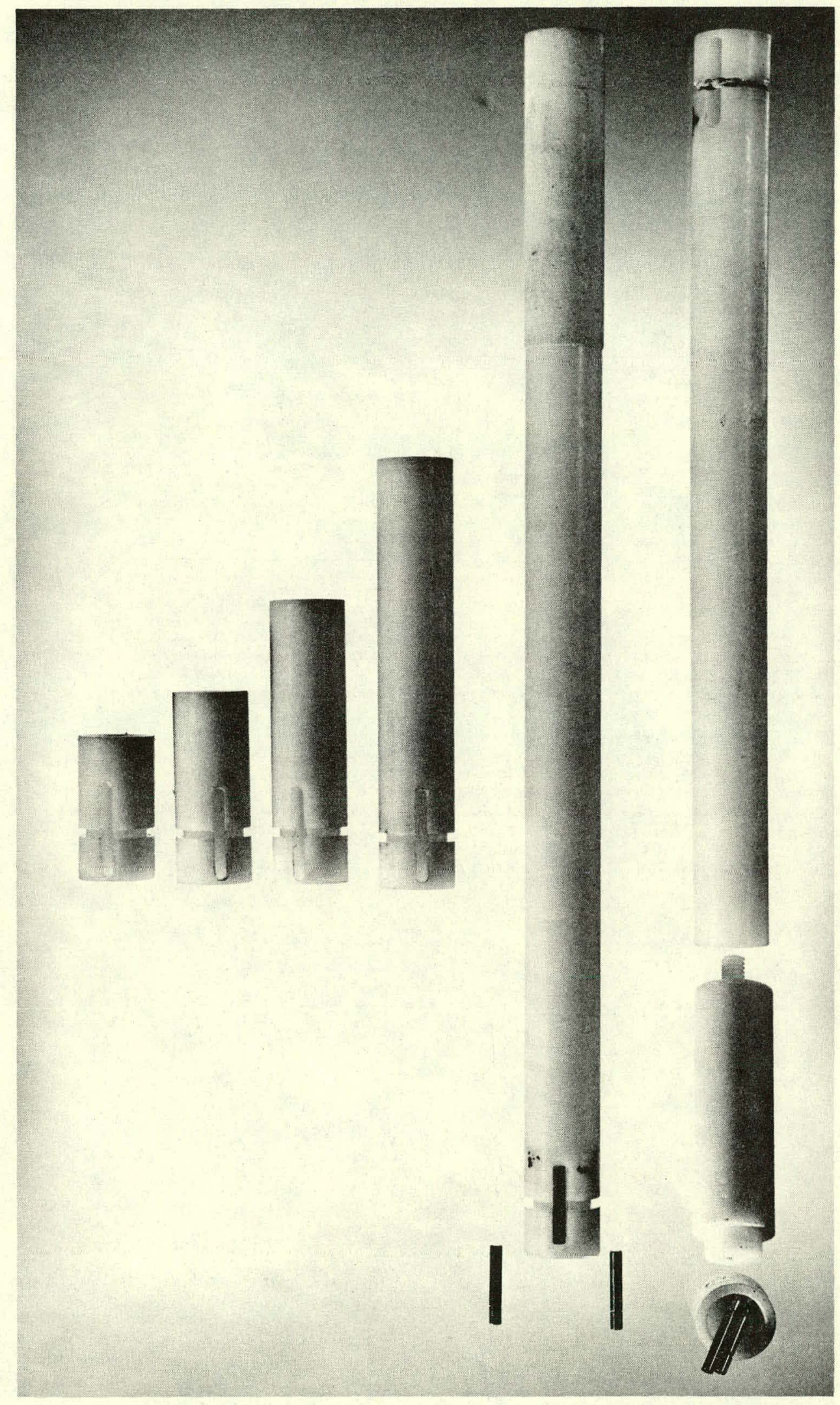

FIGURE 7 


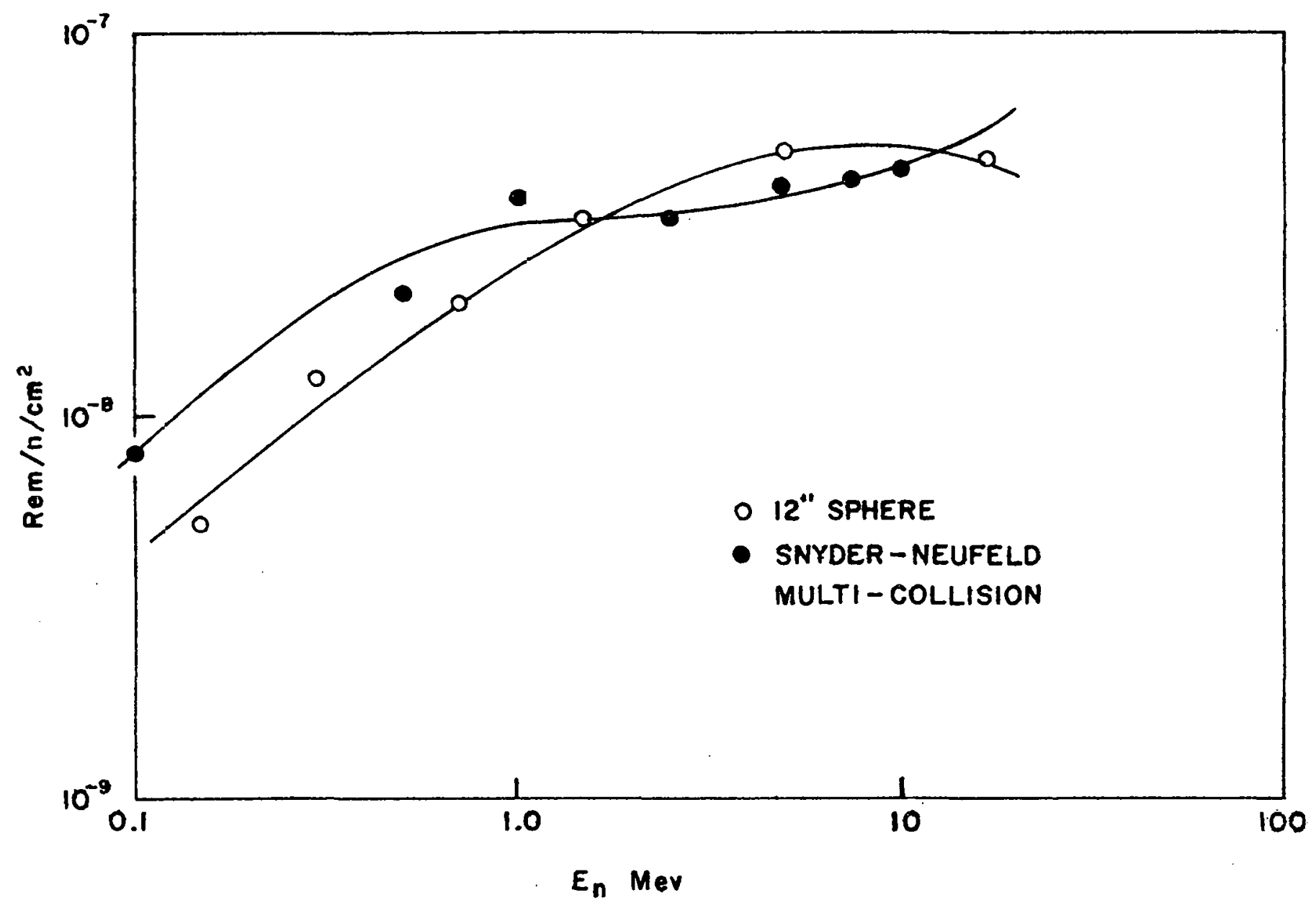

Fig. 8. RESPONSE OF LIF PHOSPHOR IN A 12 " POLYETHYLENE MODERATING SPHERE 


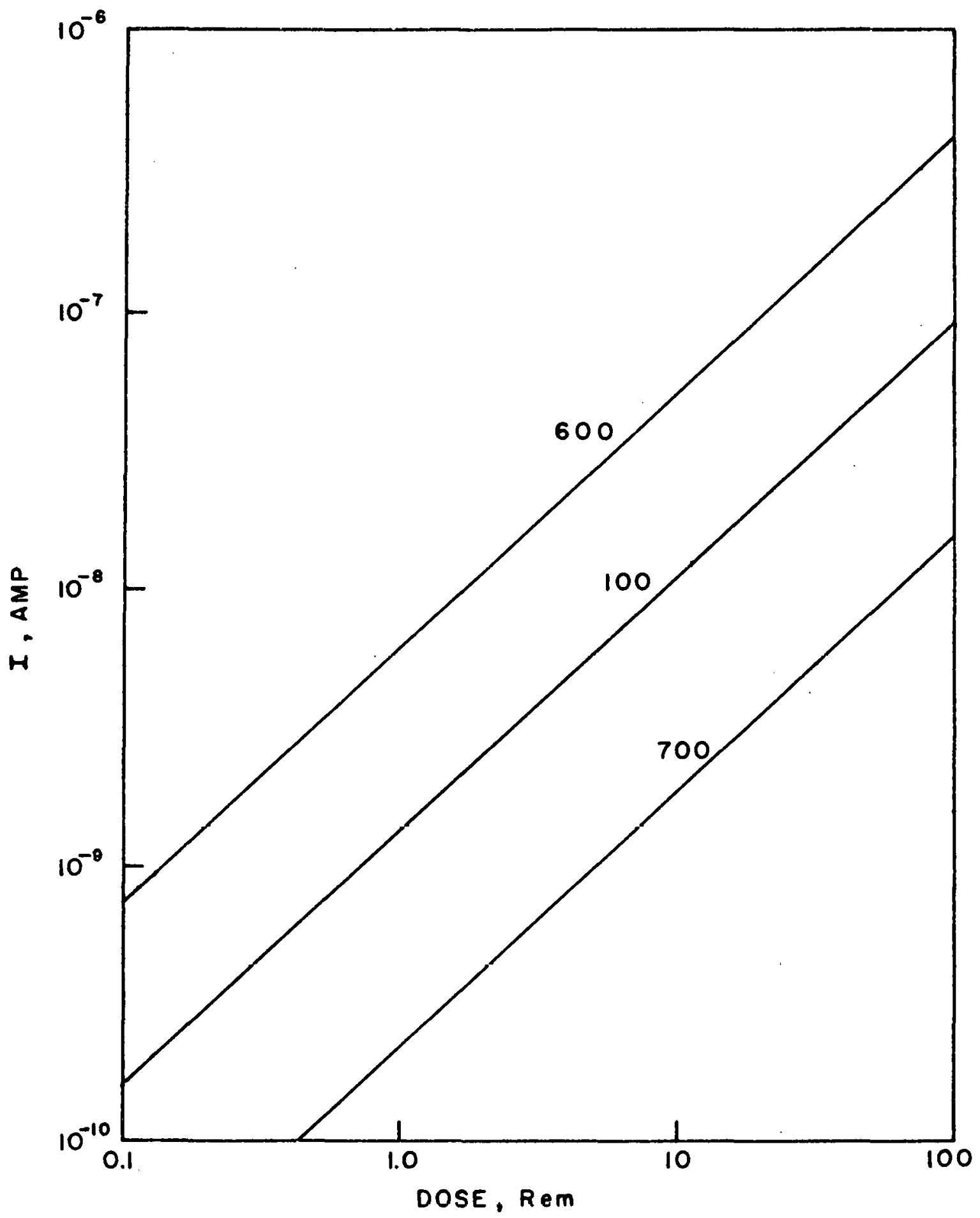

Fig. 9 PU-Be NEUTRON DOSE RESPONSE OF TLD 100, 600,8700 PHOSPHORS. 